\title{
A Research Paper on College Management System
}

\author{
Lalit Mohan Joshi \\ M.tech scholar \\ BTKIT Dwarahat, Almora, Uttarakhand
}

\begin{abstract}
This paper is aimed at developing an Online Intranet College Management System (CMS) that is of importance to either an educational institution or a college. The system (CMS) is an Intranet based application that can be accessed throughout the institution or a specified department. This system may be used for monitoring attendence for the college. Students as well as staffs logging in may also access or can be search any of the information regarding college. Attendance of the staff and students as well as marks of the students will be updated by staff. This system (C.M.S ) is being developed for an engineering college to maintain and facilitate easy access to information. For this the users must be registered with the system after which they can access as well as modify data as per the permissions given to them. CMS is an intranet based application that aims at providing information to all the levels of management with in an organization. This system can be used as a knowledge/information management system for the college. For a given student/staff (technical/Non-technical) can access the system to either upload or download some information from the database.
\end{abstract}

\section{INTRODUCTION}

The title of the project is "COLLEGE MANAGEMENT SYSTEM FOR COLLEGE" (CMS). CMS is defined as an application based on Intranet that aims to all the levels of management providing information within an organization. This system can be used as a information management system for the college.

For a given student/staff (Technical / Non-technical) the Administrator creates login id \& password, using these student/ staff (Technical / Non-technical) can access the system to either upload or download some information from the database.

The front-end will be HTML pages for client side validation with Java Script where as all business logics will be in Java reside at middle layer. third layer of database will be intereacted with these layers, which would be Oracle database. The web server would be Tomcat 5.5 version. Server have Tomcat5.5 as web server is required to start working on this project environment like Java Runtime Environment (JRE) as development environment and Oracle $10 \mathrm{~g}$ as database

The project is divided into 6 scenarios; each scenario can be developed independently. And knowledge of Java with oracle $10 \mathrm{~g}$ is desirable to execute this project.

\section{PURPOSE OF DOCUMENT}

This document is the Software Requirement Specification (SRS) for the College Management System for College (CMS) project .The purpose of this document is to describe the functionality, requirements and general interface of the CMS.

\section{SCOPE FOR DEVELOPMENT OF THIS PROJECT}

The requirement of the user is to

- Access/ Search information.

- Login to the system through the first page of the application

- Change the password after logging into the system

- View/change his/her details.

- Can get help through the help option to view different features of the system.

- Students can give feedback on college/staff/any other student.

An admin login should be present who can read as well as remove any uploads

\section{OVERVIEW OF DOCUMENT}

This document describes the product and its requirements and constraints. It provides a primarily non-technical description of the project targeted towards external audiences. This section includes information such as data requirements, functional requirements, and a general description of the product and its interaction with users from the perspective of the client. Section 3 provides specific technical requirements as the team understands them at this time and is intended for an internal audience. This section includes information such as external interface requirements, performance requirements, and any other technical requirements needed to design the software.

\section{GENERAL DESCRIPTION}

User Characteristics: The target audience for CMS product is the college students/staff (Technical/Nontechnical). The users for this system are

Administrator - The Super user of the system.

Student - A user with limited access rights.

Staff - A user of the system who has more access rights than a normal user.

\section{Product Perspective}

The product will be a standalone application and may be run on multiple systems within an Intranet network. The product will require a keyboard, mouse and monitor to interface with the users. The minimum hardware requirements for the product are specified in this document.

Overview of Functional Requirements The client requires the following features: 
- The administrator governs the working of the system.

- The staff can view the student's details.

- A mechanism to uniquely identify each student

- The students can view their marks/attendance/exam schedules .

- The system should have a login.

- The system should have help feature.

\section{Non functional requirements}

\section{CLIENT:}

Hardware platform:- PIII or above with

RAM of 128 or $20 \mathrm{~GB}$ or above Hard disk.

Software Platform:- Java Enabled Browser

\section{SERVER:}

Hardware Platform:- PIII or above with

RAM of 128 or above MB,20GB or above of Hard Disk.

\section{Software Platform:-}

HTML,Java,JavaScript,Oracle10g,tomcat5.0, windowsserver2 003.

\section{USER VIEW OF PRODUCT USE:}

The front view of the system consists of different services provided by the system and a login page with which a user is prompted to login in to the system through his user name and password. Upon the student's login, his/her details are updated in to the system. When all data is entered, the student can not only view their details but also view their exams and report details. When the student's session ends, all data is saved. Staff can also login to the system with their id and password and has access to the system.

There will be a special login name and password (to prevent students in updating their details other than profile) to allow the teacher to access all student data in a table form. Here, the administrator can add students and staff to the system and change student and staff details.

\section{SPECIFIC REQUIREMENTS:}

\section{External Interface Requirements:}

- $\quad$ Simple, Attractive, User Friendly

- $\quad$ Self-Contained, Consistent, Self-Explanatory

- $\quad$ Robust.

\section{Main modules of the system:}

Campus Information: This module gives the information about

Buildings/Blocks: It contains the information about the total number of blocks present in the campus and also the number of rooms present in each block.

- Laboratories: This gives the information about the number of laboratories present in each department.

- Buses: This gives the count of the buses deployed by the management.
- Library: students can borrow/return and can view status of books present in the library

Administration: This module deals mainly with,

- Admission: This mainly deals registering the students/staff and assigning them with a login id and password.

- Accounts: This keeps track of the financial details of the college.

- Hostel: It gives information about the college hostel for both boys and girls.

- Bus Routes: This maintains the route details of the buses.

Department Information: This module gives the information about,

- Course: This contains the information about the number of the courses offered by the college and number of seats present in each.

- Staff: This contains the number of staff available in each department.

- Infrastructure: This has the details of the assets allotted for each department.

- Syllabus: This provides the academic syllabus of the students from different branches.

Staff Information: This module deals mainly with,

- Profile: This provides personal details of the staff.

- Attendance: This provides the staff with his/her attendance details.

- Salary: This provides the staff with his/her salary details.

- Feedback: This feature enables the staff to provide feedbacks to the management.

- View Student Details: This provides the staff to view the student details.

Student Information: This module gives information about,

- Profile: This provides personal details of the student.

- Attendance: This provides the student with his/her attendance details.

- Marks: This provides the internal/external marks of a student.

- Feedback: This feature enables the student to provide feedbacks to the management.

- Remarks: It contains the remarks written by the faculties about a student.

- Change Password: Provides the student to change his/her password.

Examination Branch:_This module contains the information about, 
- Examination Form: This gives the information about the issue of the examination form.

- Results: This contains the internal/externals marks of a student.

- Attendance: It maintains the attendance of all the students (in order to issue the examination form).

- Schedule: This has the various examinations schedules/timetables.

- Seating Arrangement: This has the seating arrangements for the various examinations.

\section{SYSTEM DESIGN}

PURPOSE: Purpose of College Management System for a College (CMS) Design Document is to describe the design and the architecture of CMS. The design is expressed in sufficient detail so as to enable all the developers to understand the underlying architecture of CMS. Logical architecture of JDBC driver, Server, DML, DDL, Session and Data Store are explained.

\section{TARGET AUDIENCE}

This Design document is intended to act as a technical reference tool for developers involved in the development of College Management System (CMS).This document assumes that you have sufficient understanding of the following

\section{Concepts}

- $\quad$ RDBMS and its various component modules.

- $\quad \mathrm{SQL}$

- Java and JDBC

- Interaction Diagrams

- Classes and Interfaces

\section{PRE-REQUISITES:}

CMS requires Java JRE 1.5 or higher. Since CMS is written in Java, it can run on any platform that supports the Java runtime environment 1.5 or higher. The compiled files are contained in Java Archives (JAR's) and have to be defined in the CLASSPATH environment variable.

\section{Top Level Interaction Diagram}

\section{Logical architecture of JDBC driver, Server, DML, DDL, Session and Data Store}

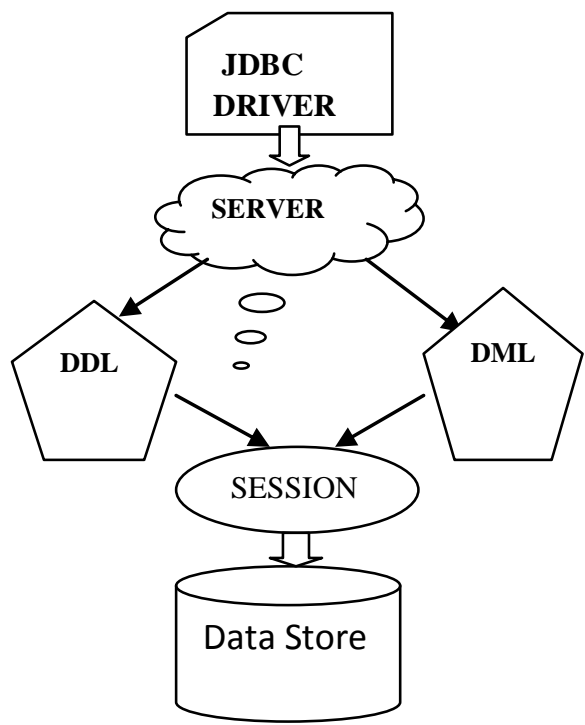

\section{ARCHITECTURAL STRATEGIES:}

The architectural design of a software project is simply the design of the entire software system. This includes the hierarchy of the modules and also which modules are present in the system. A good architectural design will create a clear and fair balance between cohesion (each module has only one distinct purpose), coupling (no two modules depend completely on each other), abstraction (seeing modules in full and not in detail), hierarchy (logical modules stem from others) and partitioning (logically grouping modules together) of the software modules 
Logical view:

It provides the user with an abstract view of the overall system functionality.

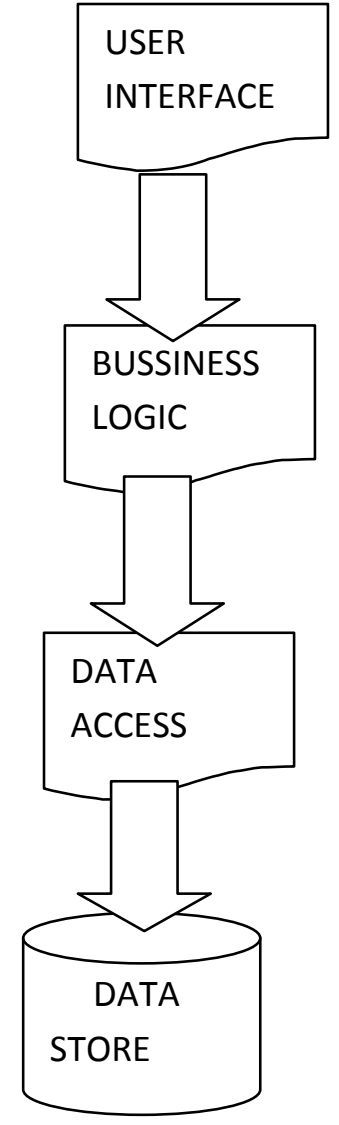

Fig. Abstract view of CMS

\section{DATA FLOW DIAGRAMS:}

- The whole architectural structure stems from the original flow design. Below are the Level 0, Level 1, Level 2 and Level3 Data Flow Diagrams (DFD).
The diagrams below more accurately portray the data flow through our system. These diagrams take precedence over the diagrams in the requirements document.

\section{Level 0 DFD}

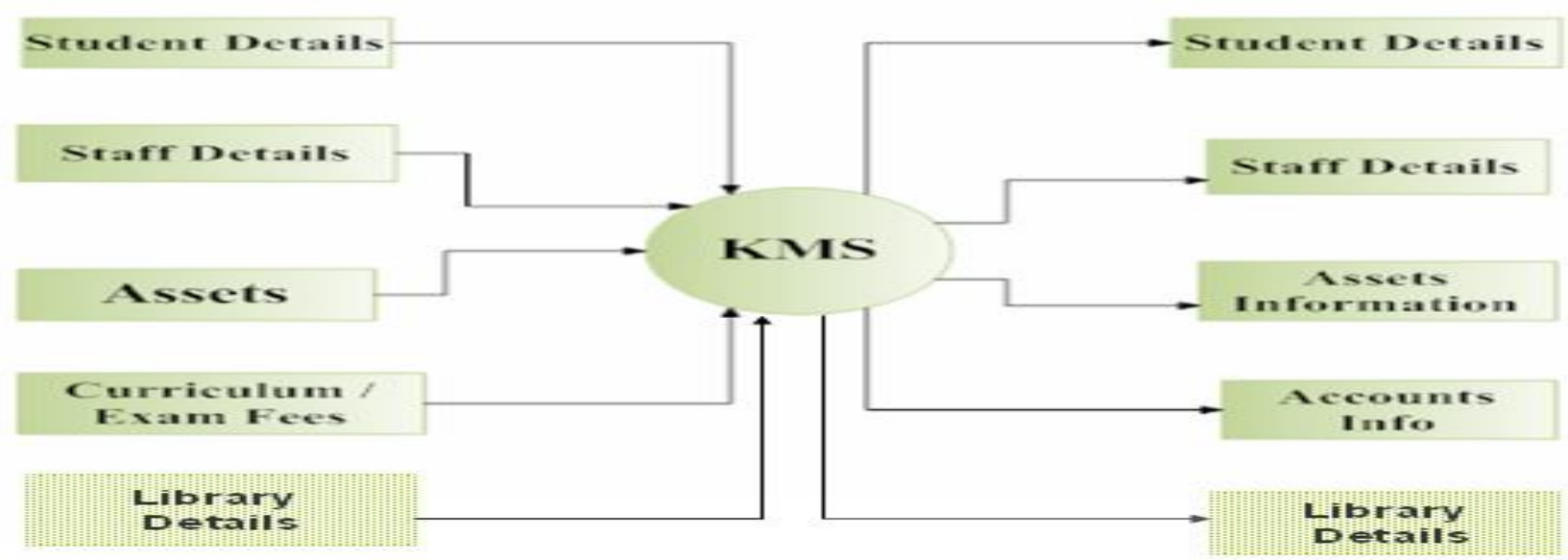




\section{Level 1 DFD}

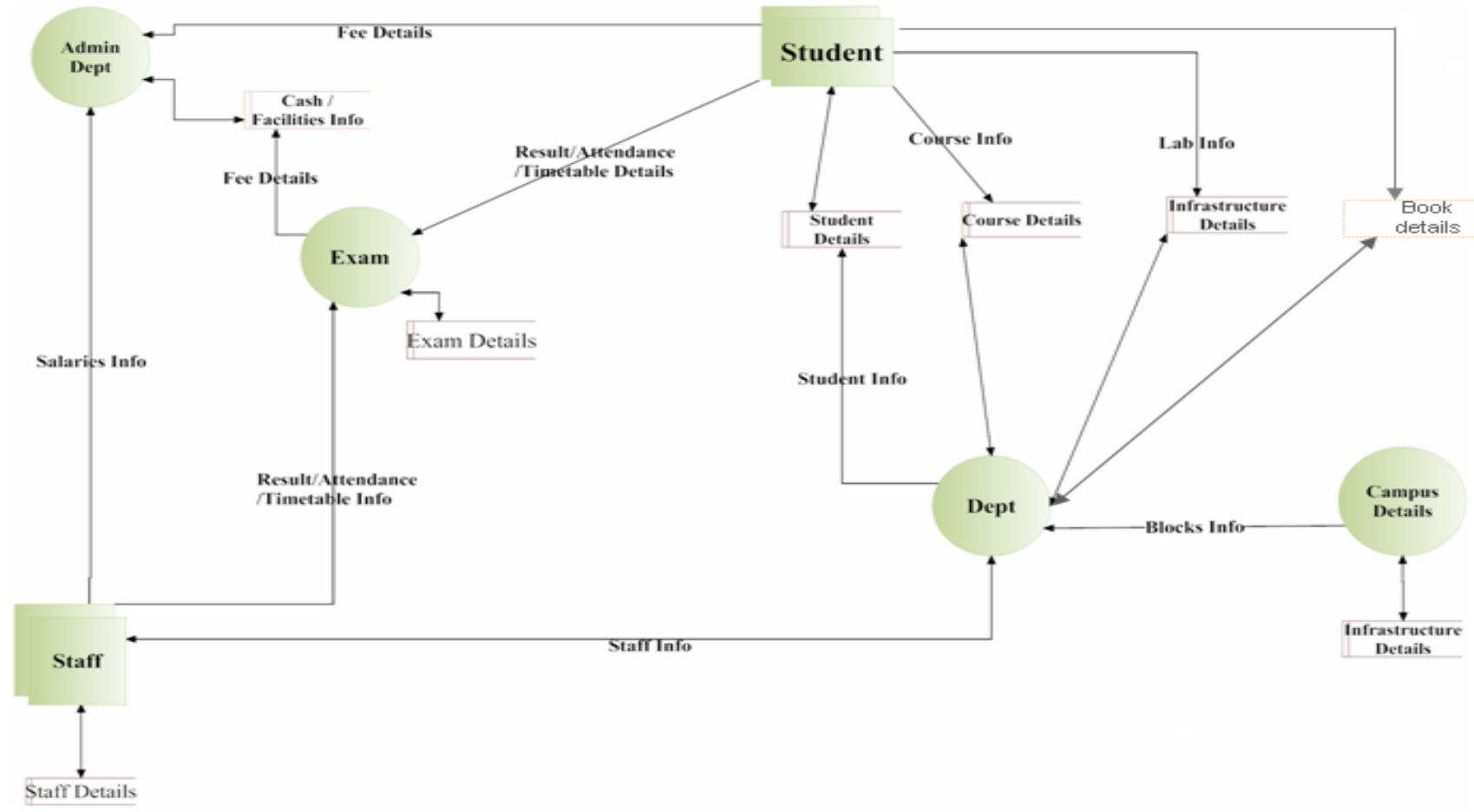

Level 2 for DEPARTMENT

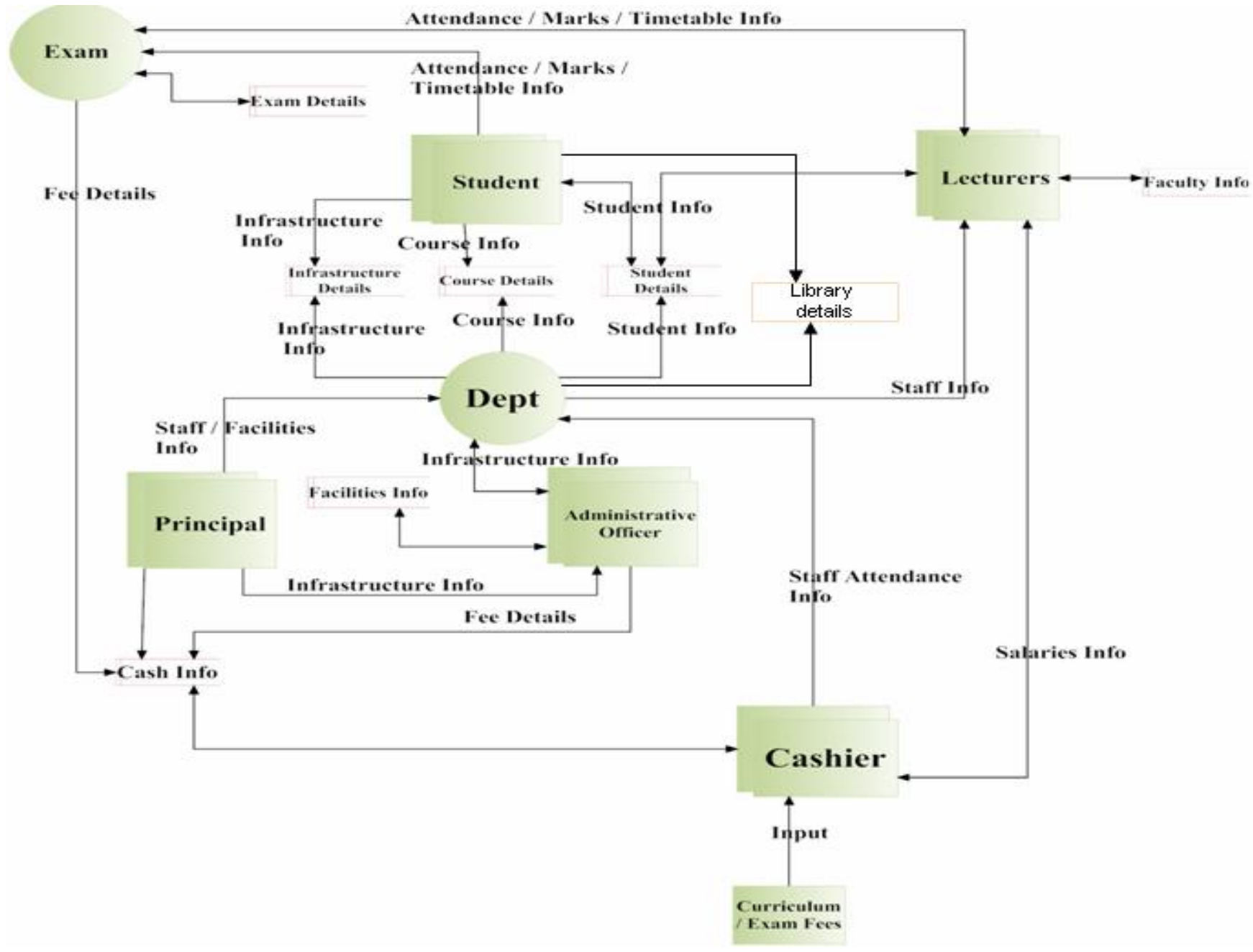




\section{Level 2 for ADMIN}

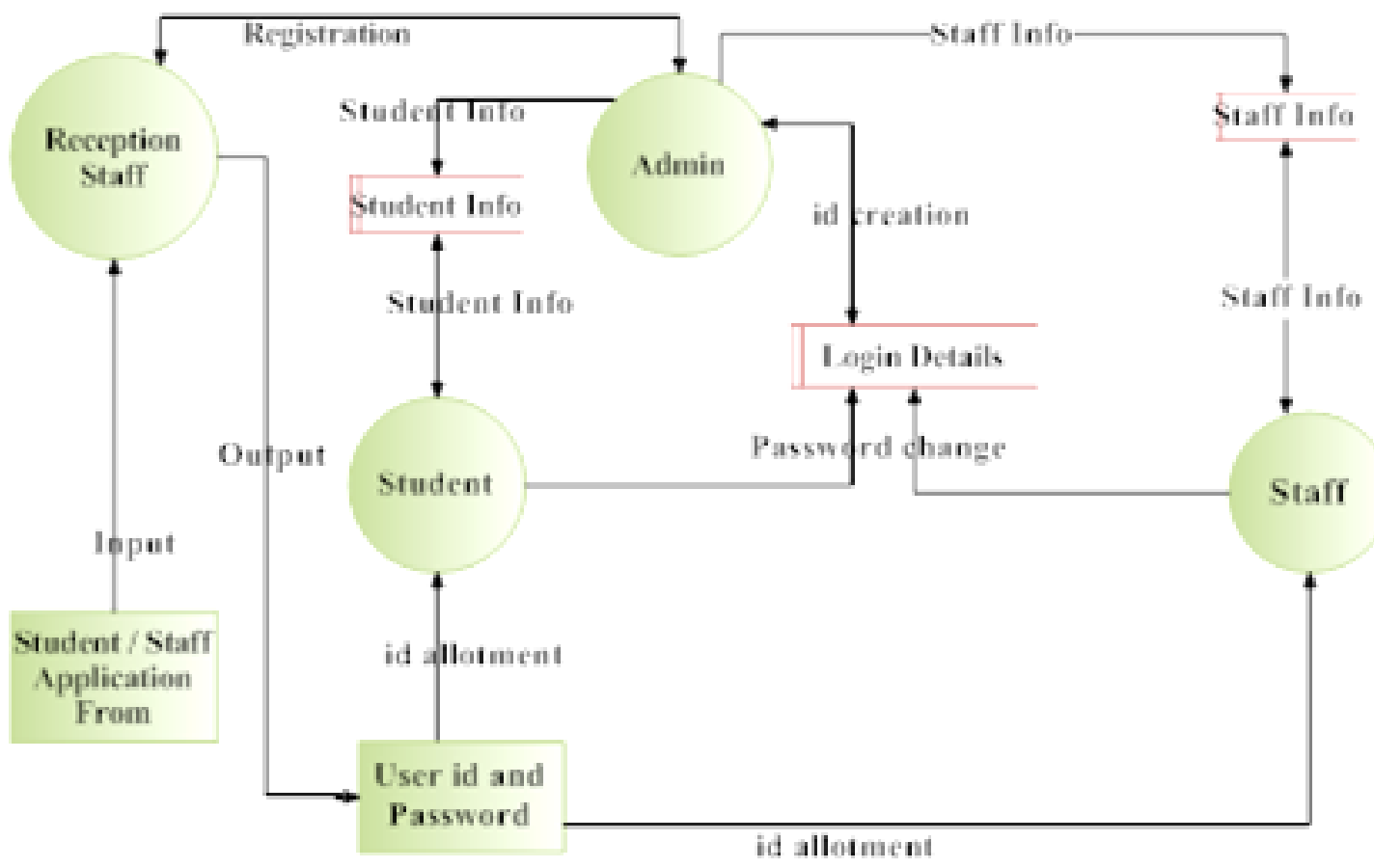

Table 1 for USERS

\begin{tabular}{|c|c|c|c|c|c|c|}
\hline \multicolumn{4}{|c|}{ Table no: } & \multicolumn{3}{|c|}{1} \\
\hline \multicolumn{4}{|c|}{ Table Name: } & \multicolumn{3}{|c|}{ Users } \\
\hline \multicolumn{3}{|c|}{ Table Description: } & & \multicolumn{3}{|c|}{$\begin{array}{l}\text { Contains usernames and passwords of all the users in the } \\
\text { system. }\end{array}$} \\
\hline Seq no & Column name & Column description & Column type & PK/FK? & $\begin{array}{l}\text { Null/Not } \\
\text { Null }\end{array}$ & Remarks \\
\hline 1 & User name & User name & VarChar & PK & Not Null & \\
\hline 2 & Password & Password & VarChar & & & \\
\hline 3 & Designation & Admin/student/staff & varChar & & & \\
\hline
\end{tabular}

\section{Relationships: None}

\section{Constraints:}

- Key Constraints: username is the primary key and must be unique.

- Referential Integrity: N/A

- Check Constraints: None

- Domain Constraints: None

- $\quad$ Expected Volume: None

Table 2 for STUDENTS

\begin{tabular}{|l|l|l|l|l|l|l|}
\hline \multicolumn{2}{|l|}{ Table No: } & 2 \\
\hline Table Name: & \multicolumn{2}{l|}{ Student } \\
\hline Table Description: & $\begin{array}{l}\text { Contains all the details of students i.e student name, address, } \\
\text { phone number, etc. }\end{array}$ \\
\hline Seq no & Column Name & Column Description & $\begin{array}{l}\text { Column } \\
\text { Type }\end{array}$ & PK/FK? & $\begin{array}{l}\text { Null/Not } \\
\text { Null }\end{array}$ & Remarks \\
\hline 1 & Studentid & $\begin{array}{l}\text { User name of the } \\
\text { student }\end{array}$ & Varchar & PK & Not Null & \\
\hline
\end{tabular}




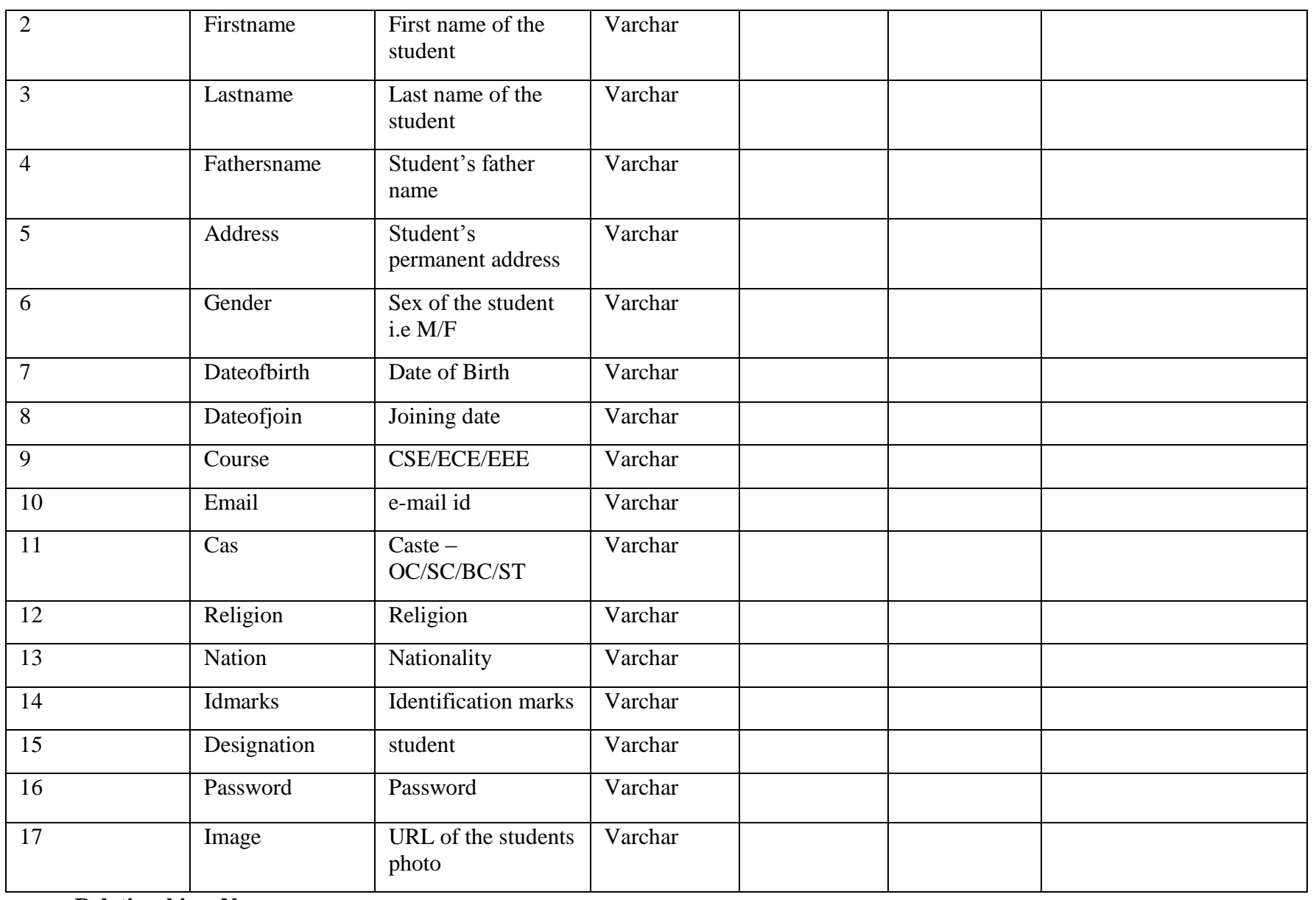

Relationships: None

\section{Constraints:}

- Key Constraints: student id is the primary key and must be unique.

- Referential Integrity: N/A

- Check Constraints: None

- Domain Constraints: None

- Expected None: None 


\section{TABLE 3 for STAFF}

\begin{tabular}{|c|c|c|c|c|c|c|}
\hline \multicolumn{4}{|c|}{ Table No: } & \multicolumn{3}{|c|}{3} \\
\hline \multicolumn{4}{|c|}{ Table Name: } & \multicolumn{3}{|l|}{ Staff } \\
\hline \multicolumn{4}{|c|}{ Table Description: } & \multicolumn{3}{|c|}{$\begin{array}{l}\text { Contains all the details of staff i.e. staff name, address, phone } \\
\text { number, etc. }\end{array}$} \\
\hline Seq no & Column Name & Column Description & $\begin{array}{l}\text { Column } \\
\text { Type }\end{array}$ & $\mathrm{PK} / \mathrm{FK} ?$ & Null/Not Null & Remarks \\
\hline 1 & employeeid & $\begin{array}{l}\text { User name of the } \\
\text { staff }\end{array}$ & Varchar & $\mathrm{PK}$ & Not Null & \\
\hline 2 & Firstname & $\begin{array}{l}\text { First name of the } \\
\text { staff }\end{array}$ & Varchar & & & \\
\hline 3 & Lastname & $\begin{array}{l}\text { Last name of the } \\
\text { staff }\end{array}$ & Varchar & & & \\
\hline 4 & Address & $\begin{array}{l}\text { Staff's permanent } \\
\text { address }\end{array}$ & Varchar & & & \\
\hline 5 & Gender & $\begin{array}{l}\text { Sex of the staff i.e } \\
\text { M/F }\end{array}$ & Varchar & & & \\
\hline 6 & Date of birth & Date of Birth & Varchar & & & \\
\hline 7 & Date of join & Joining date & Varchar & & & \\
\hline 8 & Phone No. & Phone number & Varchar & & & \\
\hline
\end{tabular}

\section{Relationships: None}

\section{Constraints:}

Key Constraints: employee id is the primary key and must be unique.

- Referential Integrity: N/A

- Check Constraints: None

- Domain Constraints: None

- Expected Volume: None

Table 4 for FEEDBACK

\begin{tabular}{|c|c|c|c|c|c|c|}
\hline \multicolumn{4}{|c|}{ Table No: } & \multicolumn{3}{|c|}{4} \\
\hline \multicolumn{4}{|c|}{ Table Name: } & \multicolumn{3}{|c|}{ feedback } \\
\hline \multicolumn{4}{|c|}{ Table Description: } & \multicolumn{3}{|c|}{ Contains all the feedback given by the staff } \\
\hline Seq No & Column Name & Column Description & $\begin{array}{l}\text { Column } \\
\text { Type }\end{array}$ & PK/Fk? & $\begin{array}{l}\text { Null/Not } \\
\text { Null }\end{array}$ & Remarks \\
\hline 1 & fromuserid & Sending userid & Varchar & & & \\
\hline 2 & Feedbackon & College/Staff/students & Varchar & & & \\
\hline 3 & Comments & Comments & text & & & \\
\hline 4 & Touserid & Destinationuserid & Varchar & & & \\
\hline 5 & Pdate & Current date & Date & & & \\
\hline
\end{tabular}

Relationships: users 


\section{Constraints:}

- Key Constraints: user id is the primary key and must be unique.

- Referential Integrity: user id match with user id in users table

- Check Constraints: None

- Domain Constraints: None

- $\quad$ Expected Volume: None

TABLE 5 :FOR ATTENDANCE

\begin{tabular}{|l|l|l|l|l|l|l|}
\hline \multicolumn{2}{|l|}{ Table No: } & \multicolumn{2}{l|}{5} \\
\hline \multicolumn{2}{|l|}{ Table Name: } & \multicolumn{3}{l|}{ Attendance } \\
\hline \multicolumn{2}{|l|}{ Table Description: } & \multicolumn{3}{l|}{ Contains the attendance of the students/staff. } \\
\hline Seq No & $\begin{array}{l}\text { Column } \\
\text { Name }\end{array}$ & $\begin{array}{l}\text { Column } \\
\text { Description }\end{array}$ & $\begin{array}{l}\text { Column } \\
\text { Type }\end{array}$ & PK/FK? & $\begin{array}{l}\text { Null/Not } \\
\text { Null }\end{array}$ & Remarks \\
\hline 1 & userid & User id & Varchar & FK & & \\
\hline 2 & attendance & $\begin{array}{l}\text { Attendace } \\
\text { percentage }\end{array}$ & Varchar & & & \\
\hline
\end{tabular}

Relationships: users

\section{Constraints:}

- Key Constraints: user id is the Foreign key.

- Referential Integrity: user id match with user id in users table

- Check Constraints: None

- Domain Constraints: None

- Expected Volume: None

Table 6 for ACCOUNTS

\begin{tabular}{|c|c|c|c|c|c|c|}
\hline \multicolumn{4}{|l|}{$\mathrm{t}$} & \multicolumn{3}{|c|}{6} \\
\hline \multicolumn{4}{|c|}{ Table Name: } & \multicolumn{3}{|c|}{ Accounts } \\
\hline \multicolumn{4}{|c|}{ Table Description: } & \multicolumn{3}{|c|}{ Contains the fee details of the students. } \\
\hline Seq no & Column Name & Column Description & $\begin{array}{l}\text { Column } \\
\text { Type }\end{array}$ & PK/FK? & $\begin{array}{l}\text { Null/Not } \\
\text { Null }\end{array}$ & Remarks \\
\hline 1 & Student id & User name of the staff & Varchar & FK & & \\
\hline 2 & First name & First name of the staff & Varchar & & & \\
\hline 3 & Last name & Last name of the staff & Varchar & & & \\
\hline 4 & Course & $\mathrm{CSE} / \mathrm{EEE} / \mathrm{ECE} / \mathrm{ME}$ & Varchar & & & \\
\hline 5 & Pay for & $\begin{array}{l}\text { Nature of payment } \\
\text { (bus, College,...) }\end{array}$ & Varchar & & & \\
\hline 6 & Year of pay & Which year of the course & Varchar & & & \\
\hline
\end{tabular}




\begin{tabular}{|l|l|l|l|l|l|l|}
\hline 7 & Modeofpay & $\begin{array}{l}\text { Mode of payment } \\
\text { (DD/Cheque })\end{array}$ & Varchar & & & \\
\hline 8 & Amount & Amount Paid & Varchar & & & \\
\hline
\end{tabular}

\section{IMPLEMENTATION}

\section{CMS Home Page}

This is the home page for Knowledge management system. This page also contains the discussion forum topics. Here teaching/nonteaching staff or student can login by their id \& password.

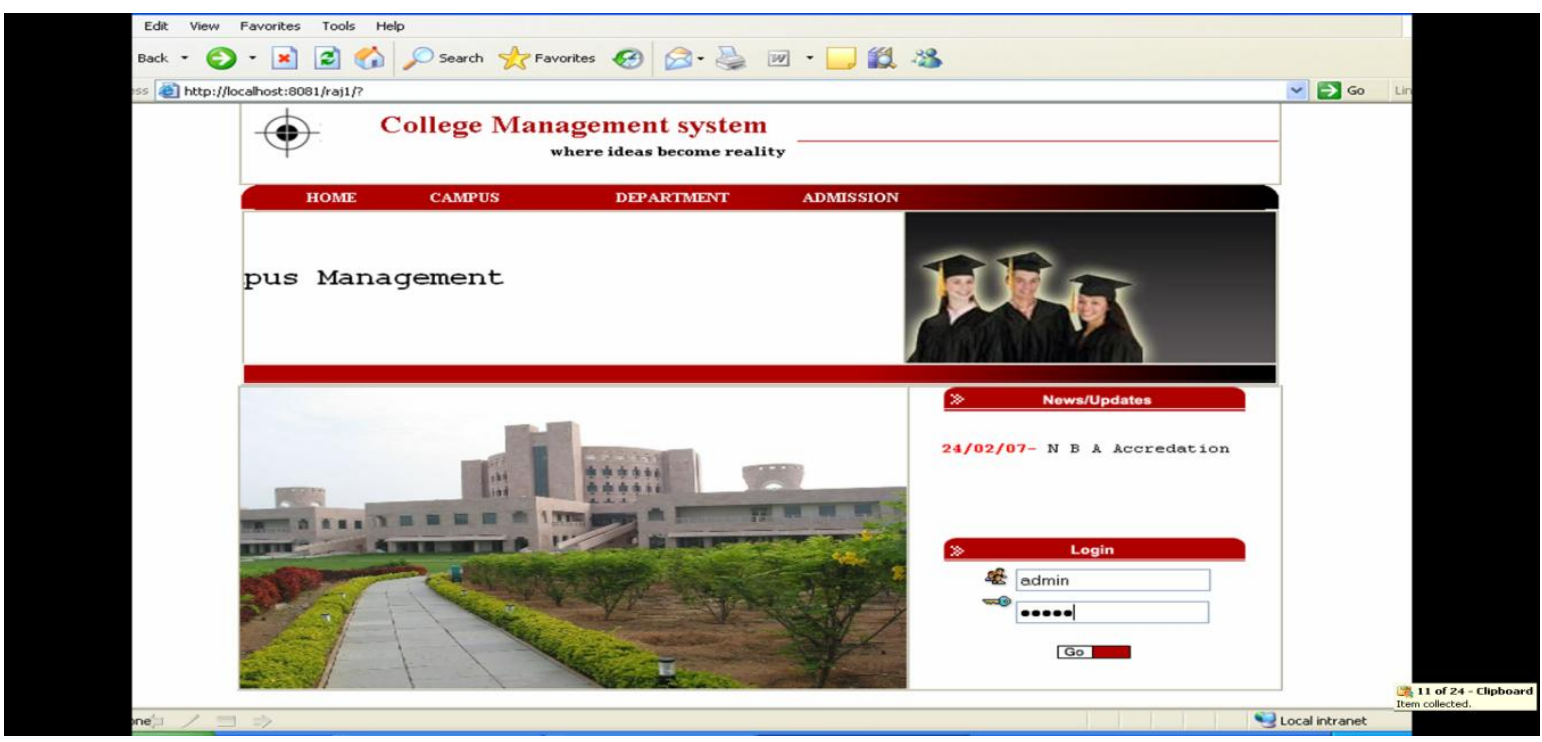

\section{ABOUT CMS}

This screen gives the overview of the Knowledge Management System i.e., the main modules in KMS

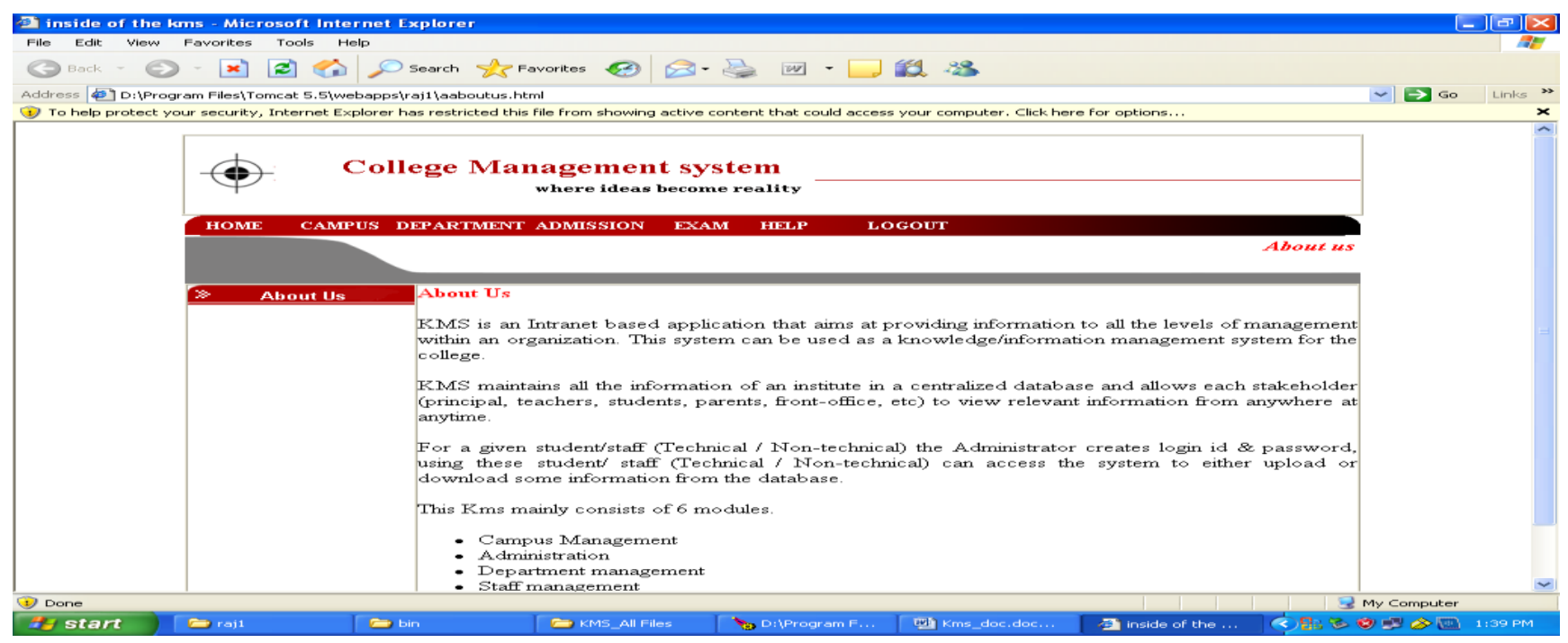

\section{INFRASTRUCTURE}

This screen tells about the student/staff admission. The admission will be provided by the administrator. The administrator provides the ID and Password for the student and staff. 


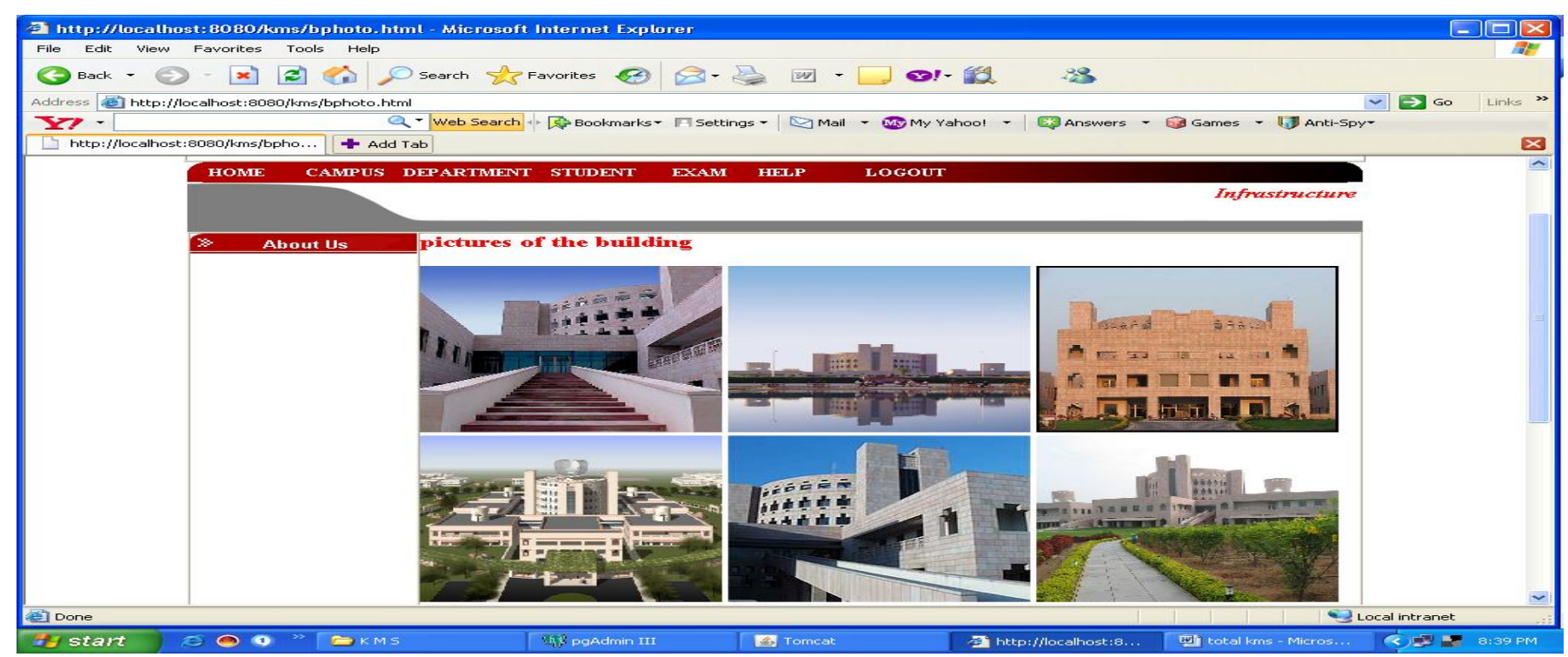

\section{STUDENT ADMISSION FORM}

The BELOW screen provides the administrator, the different fields to be filled to give an admission to student.

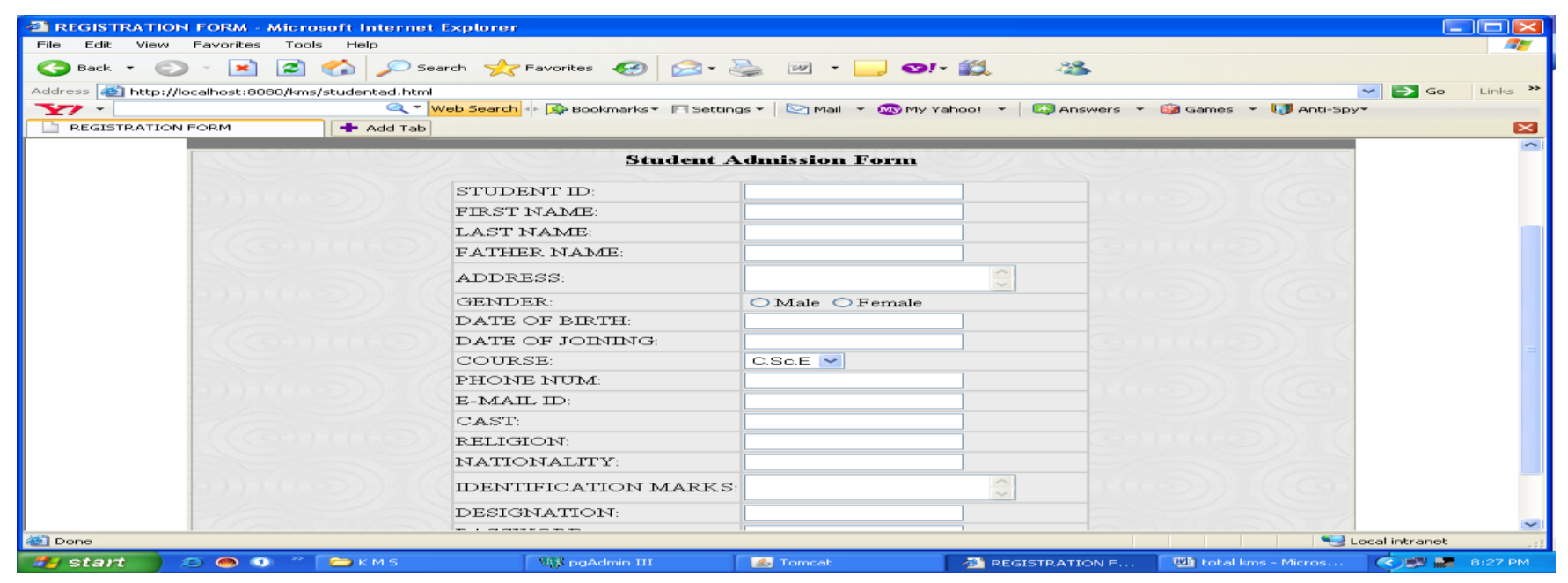

\section{SYLLABUS}

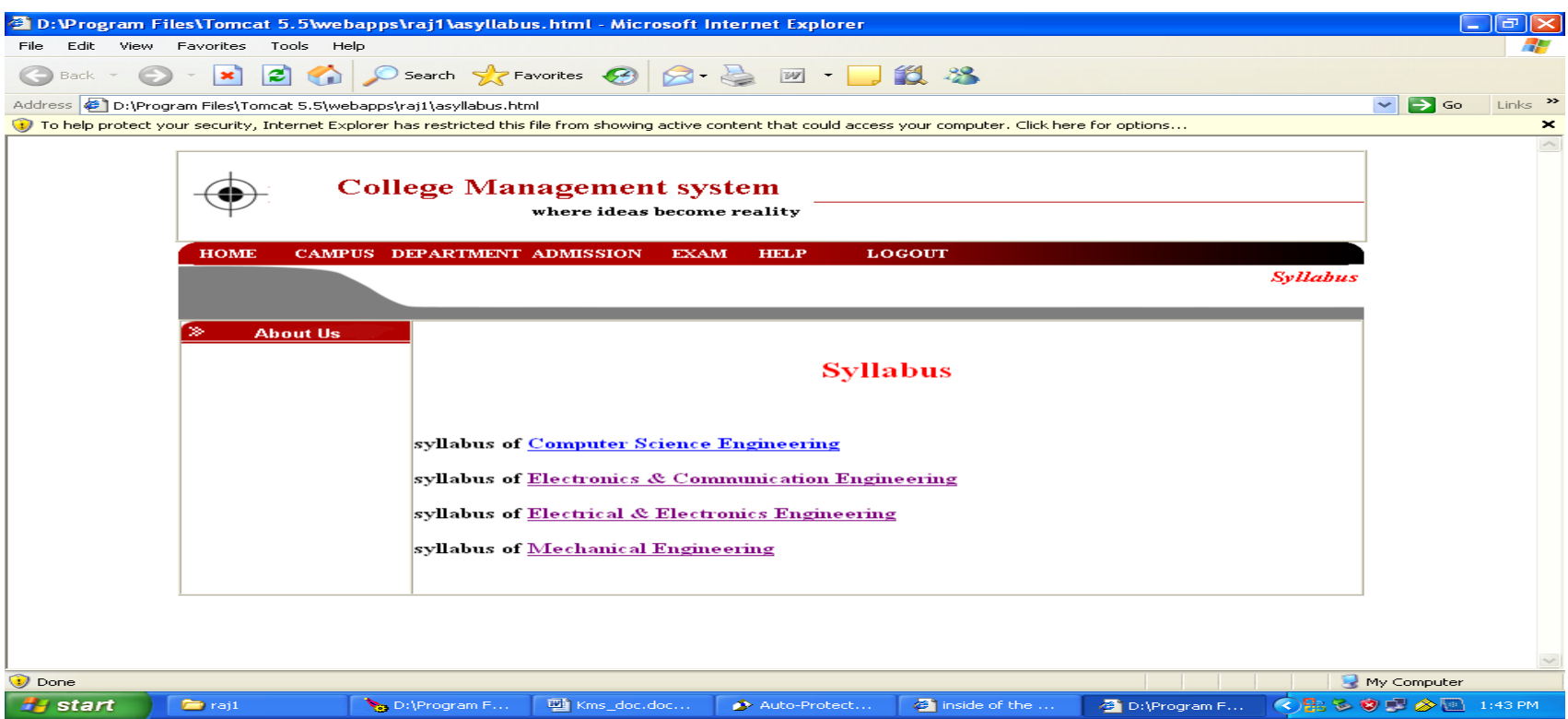




\section{TEST CASES}

\section{Test case 1: Authentication}

Test case\#: validity of name and password/priority (H, L)High

Test objective: To check the name of the user

Testdescription:Tocheckwhether username and pds valid or not

Requirements verified: valid user

Test Environment: Tomcat server, database.

\section{Test setup/reconditions:}

\section{Actions}

\section{Expected results}

Correct name and pwd

entered

The user will be logged in

Wrong name and pwd Generates an error report

entered

Pass: yes Condition pass: ... Fail: Problems/issues:

None

Notes: successfully tested and executed.

\section{Test case 2: E-mail verification}

Test case\#:- validation of e-mail/priority $(\mathrm{H}, \mathrm{L})$-High

Test objective:- validity check for e-mail

Test description:- To check whether the e-mail is valid or not

Requirements verified:- valid e-mail

Test Environment:- Tomcat server, database.

\section{Test setup/reconditions}

\section{Actions}

\section{Expected results}

Correct e-mail entered

Validation cleared

Wrong e-mail entered

Displays an error prompt

Pass: yes Condition pass: ... Fail: .......

Problems/issues: None

Notes:- successfully tested and executed

\section{CONCLUSION}

The project entitled as College Management System is the system that deals with the issues related to a particular institution.

- $\quad$ This project is successfully implemented with all the features mentioned in system requirements specification.

- The application provides appropriate information to users according to the chosen service.

- The project is designed keeping in view the day to day problems faced by a college.

\section{REFERTENCES}

[1] D B Heras, D. Otero,and F. Arguello," An eco feedback system for impro ving the sustainability Performanceof universities," in Proc. 2011 IEEE International Conference on Virtual Environments Human -Computer Interfaces and Measurement Systems, Ottawa, ON 2011 , pp. $1-6$

[2] Y Wang, B Y Sun, and F Cheng,"Electronic document based process model for image archives in niversities," in Proc. 2011 IInternational Conference on Information Technology, Computer Engineering, and Management Sciences, Nanjing, Jiangsu, pp. 57-60

[3] X. X. Xin, R. M.Wu, and H. H.Li, “A faremework model of the e-campus management system based on SOA," in Proc.2009 International Conference on Computational Intelligence and Software Engineering Wuhan, 2009, pp. 1-3[4] H. M. Weiand L. J.He, "Constructing the comprehensive academic affairs management system based on SOA," in Proc. 2009 1stInternational Conference on Information Science and Engineering, Nanjing, Jiangsu, pp. 3261-3264

[4] S. Jeyalatha, B. Vijayakumar,and G.S. Wadhwa, "Design and implementation of web based application for relational data maintenance in an university environment," in Proc. 2011 International Conference and Workshop on Current Trends in Information Technology , Dubai,pp. 105-112

[5] M-H.Lee, C -J.Yooand O.-B.Jang,"Embedded System Software Testing Using Mobile Service Based On SOA", IJAST,vol. 1, (2008), pp. 55-64

[6] S.H. Al-Daajeh, R.E Al- Qutaish and Fuad Al-Qirem, "Engineering Dependability to Embedded Systems Software via Tactics", IJSEIA, vol. 5,no.4,(2011),pp. 45 62

[7] Ming-Syan Chen, Jiawei Han, Philip S yu. Data Mining: An Overview from a Database Perspective[J]. IEEE Transactions on Knowledge and Data Engineering, 1996, 8(6):866-883.

[8] R Agrawal ,T 1 mielinski, A Swami. Database Mining: A Performance Perspective[J]. IEEE Transactions on Knowledge and Data Engineering, 1993,12:914-925.

[9] Vasant Dhat. Data Mining In Finance: Using Counterfactuals to generate knowledge from organizational information

[10] System[J].Information System, 1998,23(7):423-437.

[11] Rakesh Agrawal, Sakti Ghosh, Tomasz Imielinski, Bala lyer, Aran Swami. An Interval Classifier for Database Mining Applications[M]. CLDB92. Vancouver, British Coumbia, Vanada, 1992:560 573

[12] J Han, Y Cai, N Cercone. Knowledge Discovery in Database: An Attribute-Oriented Approach [M]. VLDB92, Vancouver, British Columbia,Canada, 1992:547-559.

[13] J.Hipp, U.Guntzer, G.Nakhaeizadeh. Algorithms for 
association generation. In Proc ACM-SIGMOD. Dallas, TX, May 2000. 1-12

[14] Advanced Embedded System Assisted GsmAndRfid Based Smartschool Management System.V. Sivasankaran, S. Suruganand, Azha.Periasamyinternational Journal Of Advanced Research In Electrical, Electronics And Instrumentation Engineering Vol. 2, Issue 7, July 2013.

[15] An Efficient Automatic Attendance System Using Fingerprint Reconstruction Technique.Josphineleela.R Research Scholar Department Of Computer Science And Engineering

[16] Sathyabamauniversity chennai,India Dr.M.Ramakrishnan Professor/Hod-It Velammal Engineering College Chennai,India(Ijcsis) International Journal Of Computer Science And Information Security,Vol. 10, No. 3, March 2012 Online Attendance Management System Using RFID with Object Counter AnkitaAgrawal and AshishBansal Department of Information Technology, ShriVaishnav Institute of Technology and Science,
Baroli, Sanwer Road, Indore, India.International Journal of Information and Computation Technology.ISSN 09742239 Volume 3, Number 3 (2013).

[17] N. M. Z. Hashim and S. N. K. S. Mohamed, "Development of Student Information System" Universitiy Teknikal Malaysia Melaka, vol. 2, pp. 256 260, August 2013.

[18] S.R.Bharamagoudar, Geeta R .B. and S.G.Totad, "Web Based Student Information Management System",

[19] Andhra Pradesh, vol. 2, pp. 2342-2348, june 2013 Agrawal R, Srikant R. Privacy-Preserving Data Mining. ACM SIGMOD Conference on Management of Data.Dallas,Texas,2000.439-450.

[20] Hand D, Mannila H, Smyth P. Principle of Date Mining, Cambridge, CA. MIT Press, 2001:1-2.

[21] Han J W, Kamber M. Data Mining: Concepts and Techniques. San Francisco: CA. Morgan Kaufmann Publishers. 2001:2-4. 